\title{
Desenvolvimento de Objetos de Aprendizagem para Matemática: uma Revisão Sistemática de Literatura
}

\author{
Eli Sales Muniz Lima ${ }^{1}$, Dennys L. Maia ${ }^{1}$ \\ ${ }^{1}$ Instituto Metrópole Digital (IMD) - Universidade Federal do Rio Grande do Norte \\ (UFRN) - CEP 59078-970 - Natal - RN - Brazil \\ elisales@ufrn.edu.br, dennys@imd.ufrn.br
}

Abstract. The teaching and learning of Mathematics still is a great challenge for Brazilian education. Learning Objects (LO) have become an alternative to helping teachers in this task. This article consists of a Systematic Review of Literature (SRL) on published articles on the use experience and development of LOs for Mathematics. 46 articles were selected, which they were cataloged by thematic unit and stages of brazilian Basic Education. Resulting in a shortage of articles with subject of Probability and Statistics, as well the LOs with defined target audience for Kindergarten.

Resumo. O ensino e aprendizagem de Matemática ainda é um grande desafio para educação brasileira. Os Objetos de Aprendizagem (OA) se tornaram uma alternativa para o auxílio dos professores nesta tarefa. Este artigo consiste em uma Revisão Sistemática de Literatura sobre os artigos publicados quanto ao experiências de uso e desenvolvimento de OAs para Matemática. 46 artigos foram selecionados, dos quais foram catalogados por Unidade temática $e$ etapas da Educação Básica. Resultando em uma carência de artigos com a temática de Probabilidade e Estatística, assim como, OAs com público-alvo definido para Educação Infantil.

\section{Introdução}

O uso de tecnologias digitais está cada vez mais difundido na sociedade. A popularização do uso de computadores, smartphones e tablets, junto com a facilidade de acesso à internet, vêm contribuindo para o acesso de informação por grande parte da população. Inclusive em escolas onde é comum haver laboratório de informática, salas equipadas com projetores e, inclusive, outros dispositivos que sua utilização na escola pode tornar educacional, como é o caso dos smartphones. Além disso, como descrito por Almeida e Valente (2011), os alunos se adequam com essas novas tecnologias e com o mundo digital de forma mais satisfatória do que os professores.

É benéfico para a educação utilizar esses recursos tecnológicos para o processo de ensino e aprendizagem, sobretudo quando oportunizam aos alunos o protagonismo do seu aprendizado, explorando as tecnologias digitais para o teste de ideias ou elaboração de conteúdos. Nesse sentido, as metodologias ativas se encaixam muito bem com os avanços dessas tecnologias. Isto é fundamental sobretudo em disciplinas que, historicamente, carregam o estigma de difícil, como é a Matemática.

Rolkouski e Vianna (2015) destacaram alguns inconvenientes na prática da Matemática escolar, como: a não vinculação da Matemática escolar com a da realidades 
VIII Congresso Brasileiro de Informática na Educação (CBIE 2019)

Anais do XXV Workshop de Informática na Escola (WIE 2019)

dos alunos; a permanência de alguns professores nos modelos tradicionais e ainda em livros didáticos de 20 a 30 anos atrás; e o ensino trabalhado na técnica, encobrindo os conceitos matemáticos dificultando a compreensão crítica do aluno quanto ao tema.

Com a perspectiva do uso das tecnologias digitais alinhada a metodologias ativas é possível alterar essa realidade com diversas formas de representação e interação com o assunto estudado. Dentre essas que podem ser adotadas estão aqueles que Wiley (2000) chamou de Objetos de Aprendizagem (OA) e descreveu como instrumentos digitais que podem ser acessíveis, utilizados para aprendizagem de algum assunto específico e no tempo de uma aula. Assim, os OAs configuram-se como alternativas para auxiliar os professores a oferecerem outras representações acerca do assunto estudado que podem ser mais objetivas, dinâmicas, interativas. Os professores podem adotar os OAs em seus planos de aulas para diversificar as formas de explanação teórica e buscar do aluno uma posição mais ativa do processo educacional.

Muitos OAs são desenvolvidos para a Matemática. Somente na Plataforma Objetos de Aprendizagem para Matemática (OBAMA) estão disponíveis mais de 500 OAs para Matemática classificados por nível de ensino e temas curriculares da Educação Básica, acessíveis tanto por dispositivos desktops quanto mobile [Oliveira et al. 2018]. Entretanto, de acordo com Oliveira et al (2017) a unidade temática de Tratamento da Informação, componente importante do Pensamento Estatístico, era a menos contemplada o que demanda uma maior atenção dos desenvolvedores para essa área. A junção de uma análise pedagógica especializada com grupo de desenvolvedores e designers pode desenvolver valiosos OAs para auxiliar no processo de ensino e aprendizagem.

Uma Revisão Sistemática de Literatura (RSL), como visto por Kitchenham et al (2009), fornece uma evidência científica de melhor qualidade para responder uma questão. Trata-se de um método mais rigoroso que evita qualquer viés do pesquisador. Com isso, buscou-se fazer uma pesquisa para identificar outros trabalhos que denotam as áreas temáticas com escassez de objetos de aprendizagem, assim como os públicos-alvos para tais.

Este trabalho é um recorte de uma dissertação de mestrado que pretende desenvolver um OA para suprir essa demanda. Nesse sentido, o objetivo deste trabalho foi realizar uma RSL visando analisar os projetos de desenvolvimento de OAs para Matemática, especificamente para Estatística, levantando as características técnicas e pedagógicas do seu desenvolvimento. Sendo assim, uma análise quantitativa de artigos sobre o uso e desenvolvimento de OA para Matemática, destacando os assuntos e público-alvo destacados pela Base Nacional Comum Curricular (BNCC).

\section{Metodologia}

Como objetivo, foram procurados artigos que se relacionem com o contexto do ensino de Matemática com o uso de objetos de aprendizagem, sendo assim, foi separado em dois tipos de artigo: desenvolvimento do OA ou experiência de utilização do OA. Por mais que a motivação da pesquisa esteja de acordo com o desenvolvimento de um Objeto de Aprendizagem, as experiências do uso de um OA descrevem algumas dificuldades encontradas pelo pesquisador para com o seu uso, falhas encontradas pelo OA que não deveriam haver em trabalhos futuros. 
Para a pesquisa foram utilizadas fontes especializadas na área de Informática na Educação, como o SBIE, CBIE e o Ctrl+E. Contudo os resultados para as buscas após analisado os critério de inclusão e exclusão retornaram somente treze artigos. Portanto, foi feito de forma mais abrangente no portal periódicos da CAPES.

\subsection{Estratégias de busca}

Para a pesquisa foram escolhidos artigos que possuam em seus títulos ou resumos os principais pontos descritos nessa pesquisa, sendo eles: "Objeto de Aprendizagem" e "Matemática". Além disso, foi recorrido a pesquisas contendo os termos referentes também em inglês, sendo: "Learning Objects" e "Mathematics".

\subsection{Critérios de inclusão e de exclusão}

Para a inclusão dos artigos foram procurados aqueles periódicos revisados por pares, e de publicação nos últimos 5 anos, e, por fim que possuam as palavras de busca no título, resumo ou descrição fornecida pelo CAPES. Além disso, artigos que se encaixarem com o uso ou desenvolvimento de OAs para o auxílio da aprendizagem de Matemática, seja na Educação Básica ou superior.

Para a exclusão dos artigos foram retirados aqueles que não possuíam ligação precisa com o tema. Não haver correlação com ensino de Matemática de forma direta ou interdisciplinar, inexistência de experiência de uso ou o desenvolvimento de algum objeto de aprendizagem, não existir o termo "Objeto de Aprendizagem" e "Matemática" descrito no resumo ou título, análises ou comparação de objetos de aprendizagem sem haver distinção de áreas educacionais, ensino de Matemática por metodologias inovadoras ausente de experiências com o uso de OAs, link digital do artigo não disponível para acesso.

\section{Revisão da Busca}

Para os anais de eventos nacionais como SBIE, CBIE e Ctrl+E, os termos analisados foram pesquisados em português. Foram encontrados no SBIE três artigos condizentes com os critérios de pesquisa, sendo dois relacionados ao processo de desenvolvimento e um quanto a experiência de uso. Em conseguinte, nos Anais do CBIE o termo de "objeto de aprendizagem" e "matemática" obteve 3 resultados de pesquisa, sendo-os divididos como dois de desenvolvimento e um de uso. Quando no $\mathrm{C}$ trl+E, sete artigos alcançaram os parâmetros pesquisado, se dividindo em um para desenvolvimento e seis para a utilização dos OAs.

Em uma primeira análise no portal de periódicos da CAPES, com os termos pesquisados em português, foram obtidos onze resultados, porém somente sete estavam apropriados com os critérios propostos, sendo um sobre desenvolvimento de OA, e seis sobre experiências com a sua utilização. Na segunda análise na CAPES, com a busca em inglês, foram obtidos 611 resultados da pesquisa, contudo, em uma análise do resumo, foram atendidos aos critérios 27 pesquisas, sendo 8 relacionadas ao desenvolvimento de algum software com uso educacional para Matemática e $19 \mathrm{com}$ experiências de uso dessas ferramentas. 
VIII Congresso Brasileiro de Informática na Educação (CBIE 2019)

Anais do XXV Workshop de Informática na Escola (WIE 2019)

\section{Análises e Apresentação dos Resultados}

Ao serem catalogados os artigos buscou-se dividi-los nas seguintes Unidades Temáticas, disposta em Brasil (2018), descritas pela BNCC: Números, Álgebra, Geometria, Grandezas e Medidas, Probabilidade e Estatística. Vale ressaltar que houveram artigos que não puderam ser separados por área de ensino em virtude de suas características bastantes generalistas, quanto ao uso de OAs para o ensino de Matemática. Ainda assim, se obteve o seguinte gráfico.

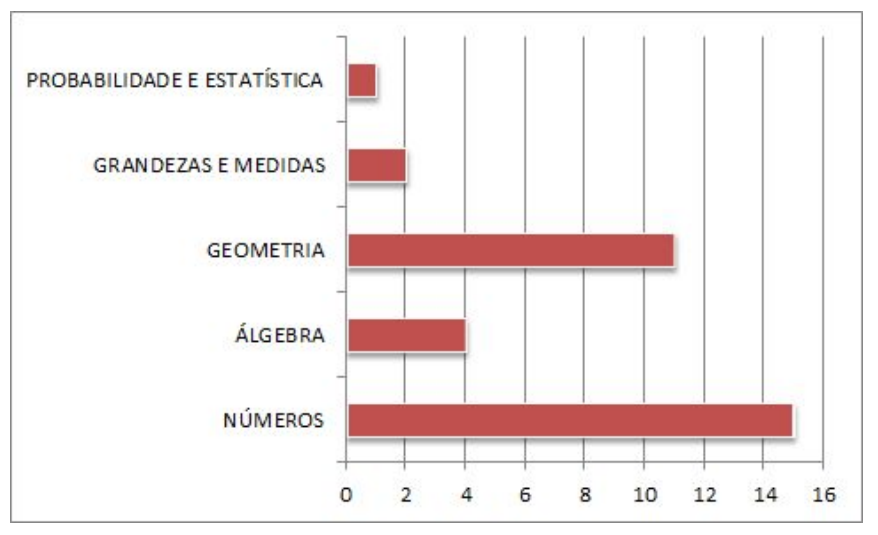

Figura 1. Quantidade de artigos por Unidades Temáticas.

Dentre os artigo procurados, vale citar o desenvolvimento do OA Números Fracionários - Algumas Ideias, de Muller et al (2015). O objetivo foi explicitar o conceito matemático de forma simples, buscando a reflexão da teoria, com a aplicação prática do conceito. Estes aspectos observados são de extrema importância, como já visto anteriormente dos inconvenientes da prática escolar no ensino de Matemática.

Ademais, é válido destacar, sobre o desenvolvimento dos OAs, somente haviam artigos dos temas: Números, Álgebra e Geometria, respectivamente, 6, 2 e 3 artigos, enquanto que nas outras áreas não possuíam nenhum artigo para o tema.

Em seguida foi analisado o público-alvo das pesquisas, novamente alertando que a totalidade dos artigos não foi obtida a sua separação nos pontos de ensino. Dessa forma, se obteve o seguinte gráfico:

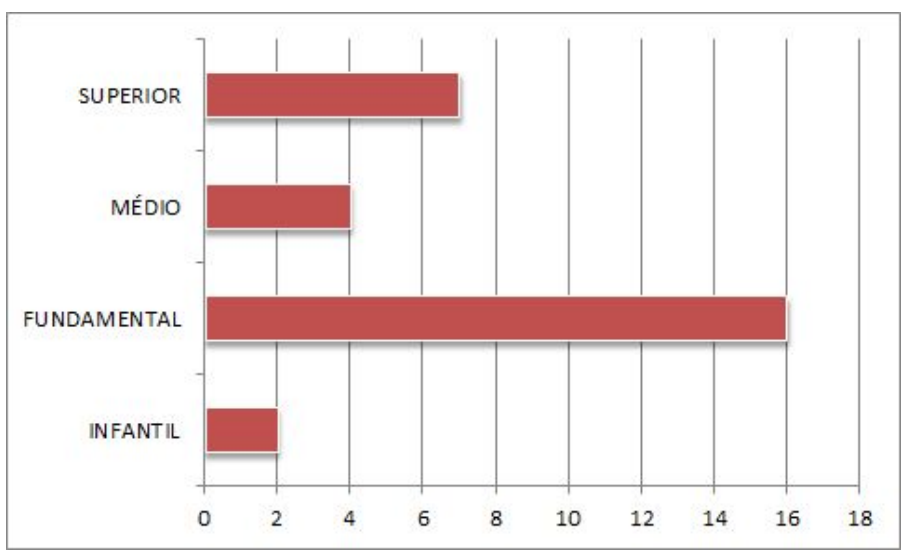

Figura 2. Quantidade de artigos por Público-Alvo. 
Sobre os artigos com ênfase no desenvolvimento, foi notado que dos sete artigos para ensino de Matemática na Educação Superior, quatro tratavam do desenvolvimento de um OA. Com relação aos outros públicos-alvos, dois são para Ensino Médio, e cinco para o Ensino Fundamental, em que somente três foi especificado o nível, sendo dois para anos iniciais e um para anos finais.

\section{Conclusões}

É notável perante os resultados expostos que há uma carência de artigos expressando o uso e o desenvolvimento de softwares de cunho educativo para o ensino de Probabilidade e Estatística. Neste parâmetro, se reforça a motivação da dissertação ao desenvolver OAs para Probabilidade e Estatística. Juntamente aos resultados mais notáveis, se juntam a produção de OA para Educação Infantil e na apresentação de conceitos de Grandeza e Medidas, e ainda artigos de experiência de aplicação de objetos de aprendizagem para turmas de Ensino Médio.

\section{Referências}

Almeida, M. E. B. e Valente, J. A. (2011) "Tecnologias e currículo: trajetórias convergentes ou divergentes?", São Paulo, Paulus.

Brasil. (2018) Ministério da Educação. Secretaria da Educação Básica. "Base nacional comum curricular." Brasília, DF. Disponível em: < http://basenacionalcomum.mec.gov.br/\#/site/inicio>. Acesso em: jun. 2019.

Kitchenham, B. Brereton O. P., Budgen, D. Turner, M. Bailey, J. Linkman, S. (2009) "Systematic literature review in software engineering - A systematic literature review”. Durham, UK, Information and Software Tecnology.

Muller, M. K.; Gonçalves, N. S.; Moraes, M. (2015). "Números fracionários - algumas ideias". In: Anais do CBIE 2015. Maceió, SBC. p.163-168.

Oliveira, A.; Silva, A.; Costa, C.; Maia, D. (2017). "Levantamento e Catalogação de Objetos de Aprendizagem para Matemática para Atualização de um Repositório”. In: Anais do Ctrl+E 2017. Mamanguape, PB: CEUR-WS. v. 1877. p. 47-58.

Oliveira, A.; Batista, S.; Oliveira, N.; Maia, D. "XYZ: Uma Plataforma para Inovação e Colaboração na Prática Docente”. In: Anais do WCBIE 2018. Fortaleza: SBC. p.156-163.

Rolkouski, E. e Vianna, C. R. (2015) "Educação Matemática: pesquisas e possibilidades" , Curitiba, Editora UTFPR.

Wiley, D. A. "Learning Object Design and Sequencing Theory", Ph. D dissertation, Provo, Utah, Brigham Young University. 